\title{
AUTOETNOGRAFIA: A CONSTRUÇÃO DA IDENTIDADE DE UMA INTERVENTORA SOCIAL
}

\author{
Priscila Dias Batista Vieira ${ }^{1}$ \\ ${ }^{1}$ Departamento de Sociologia e Psicologia da Universidade de Coimbra, Portugal. \\ prisciladias.social@gmail.com
}

\begin{abstract}
Resumo. A presente pesquisa é desdobramento de um trabalho que venho realizando, há dez anos, como interventora social, através do qual desenvolvo Projetos Sociais voltados ao empoderamento de mulheres em vulnerabilidade. Em conjunto com minha orientadora, consideramos pertinente, para o meu trabalho de conclusão do Mestrado em Intervenção Social, Inovação e Empreendedorismo (MISIE), a elaboração de uma pesquisa autoetnográfica, como oportunidade de conceber um texto teórico voltado a transcrever as experiências que contribuíram para a construção da minha identidade como uma interventora social. A elaboração de uma autoetnografia somente se justifica quando o conteúdo que será o foco da investigação possui, de fato, alguma relevância e possa trazer contribuição significativa ao campo da pesquisa sociológica. Para a composição desta pesquisa as minhas experiências pessoais serão os principais instrumentos de análise. Dentro dos procedimentos de análise estarão meus diários de campo, livros, vídeos, fotografias, roupas, entrevistas e demais registos. O contributo esperado é gerar uma produção intelectual que possa engajar, sensibilizar e inspirar mais mulheres interessadas em se tornarem interventoras sociais, com foco em desenvolver Projetos Sociais voltados a mulheres marginalizadas.
\end{abstract}

Palavras-chave: Autoetnografia; Interventor Social; Identidade; Mulheres; Vulnerabilidade.

\section{AUTOETNOGRAPHY: THE CONSTRUCTION OF THE IDENTITY OF A SOCIAL ACTOR}

Abstract. This research is an unfolding of a work I have been doing for ten years as a social intervenor, through which I develop Social Projects aimed at the empowerment of vulnerable women. Together with my mentor, we consider it pertinent for my conclusion work of the Master in Social Intervention, Innovation and Entrepreneurship (MISIE), the elaboration of an autoetnographic research, as an opportunity to conceive a theoretical text aimed at transcribing the experiences that contributed to the construction of my identity as a social actor. The elaboration of an autoetnography is only justified when the content that will be the focus of the research has, in fact, some relevance and can bring significant contribution to the field of sociological research. For the composition of this research my personal experiences will be the main instruments of analysis. My field diaries, books, videos, photographs, clothes, interviews and other registrations will be part of the analysis procedures. The expected contribution is to generate an intellectual production that can engage, sensitize and inspire more subjects interested in becoming social actors, with a focus on developing Social Projects aimed at marginalized women.

Keywords: Autoetnography; Social Intervenor; Identity; Women; Vulnerability.

\section{INTRODUÇÃO}

A presente pesquisa é desdobramento de um trabalho que venho realizando, há dez anos, como interventora social. Sou Psicóloga Social, com licenciatura em Filosofia, e hoje responsável por uma empresa social, através da qual venho desenvolvendo ações para combater as inúmeras violências, estigmas e invisibilidades de mulheres que se encontram em vulnerabilidade social. O meu objetivo de trabalho tem sido contribuir atuando com estra- 
tégias voltadas ao empoderamento dessas mulheres com quem atuo. Iniciei, em 2009, a minha trajetória profissional no Brasil trabalhando como Psicóloga no SUS (Sistema Único de Saúde) e no CRAS (Centro de Referência de Assistência Social), bem como na APAE (Associação de Pais e Amigos dos Excepcionais), com portadoras de necessidades especiais. Atuei como Professora de Filosofia em periferias e zonas rurais, além de ter sido colaboradora de diversas ONGs. Possuo experiências de atuação em relação às mulheres empregadas domésticas, obesas mórbidas, seropositivas e prostitutas. No Brasil, realizei, ainda, de forma autónoma, projetos com meninas em situação de abrigo, mulheres em hospital psiquiátrico, dependentes químicas, caiçaras, mulheres rurais, idosas, detentas em cadeia feminina, dentre outras. Na Europa, desenvolvi ações voltadas a mulheres em situação de rua em Dublin (Irlanda) e atuei com mulheres em campo de refugiados em Dunkerque (França). Já estive em visita a Projetos Sociais com mulheres na África (Marrocos e Kenya) e Ásia (Índia, Bangladesh, Vietnã e Tailândia). Com apenas 34 anos, observo que acumulei experiências e vivências que julgo não serem relevantes somente para a minha trajetória profissional ou para o meu "currículo", como muitas pessoas consideram, mas que me alteraram por inteira como pessoa, mulher e cidadã.

Quando iniciei os meus primeiros projetos, há dez anos, eu ainda não tinha dimensão do quanto essas experiências iriam expandir as minhas percepções e compreensão da complexidade que envolve a questão da saúde mental das mulheres em vulnerabilidade. $O$ objetivo deste esforço intelectual será, através do meu relato autoetnográfico, sensibilizar outras mulheres a também se tornarem interventoras sociais, com foco em desenvolver ações voltadas a mulheres marginalizadas. Na minha perspectiva, se a preocupação central da intervenção social é produzir transformação social, quanto mais pessoas o fizerem, a chance de produzirmos impacto é maior. Por essa razão, defendo que os conteúdos sobre intervenção social podem ser ampliados, não sendo direcionados somente a especialistas. Por sua tamanha importância, precisam ser disseminados numa linguagem não somente científica, para que o conceito possa alcançar um maior número de pessoas.

As demandas emocionais destas mulheres, no campo do adoecimento e sofrimento psíquico, derivavam de problemáticas de ordem sociais, nelas estão incluídas dificuldades de geração de renda que refletem em necessidades básicas como alimentação, moradia, transporte e saúde, assim como ausência de acesso a oportunidades de educação, cultura e lazer. Se essas ausências e precarizações são as razões que produziam sintomas de ordem emocionais, uma vez que são localizados, o enfrentamento destes sintomas também 
precisam ser de ordem social. Porém, será preciso inovar no desenvolvimento de outras estratégias para combate-la, pois as estratégias existentes até o momento não têm sido suficientes como observei, não somente no Brasil, mas em experiências em outros países por onde transitei. É importante que o problema da saúde mental das mulheres em vulnerabilidade envolva uma mobilização social maior, por isso defendo a importância de pensarmos a capacitação de interventores sociais para além dos moldes académicos, compreendendo a urgência de existirem mais indivíduos da sociedade capacitados para atuarem em várias frentes.

\section{AUTOETNOGRAFIA COMO INVESTIGAÇÃO QUALITATIVA}

Em pesquisa realizada não localizei uma produção teórica autoetnográfica voltados às próprias vivêcias do interventor social no que se refere a construção da sua própria identidade como tal e nas demais revisões de literatura científica, não autoetnográficas, localizei o conceito de "interventor social" tratado apenas a partir do género masculino. Essas constatações motivam-me a produzir um material teórico auto-reflexivo baseado nas minhas experiências como mulheres interventora social.

Essas reflexões conduziram-me, ao seguinte problema de investigação: quais das minhas experiências que afetaram a construção da minha identidade como interventora social podem contribuir hoje para eu oferecer capacitação para outras mulheres que também possuem interesse em desenvolverem Projetos Sociais voltados a mulheres em vulnerabilidade? Na autoetnografia, a partir da perspectiva de Ellis, Adams e Bochner (citados por Andrade, 2016, p.4) "o/a investigador/a procura relatar a sua experiência pessoal, significativa em termos culturais, mas tenta também, através da produção de textos acessíveis, atingir um público mais amplo, que a pesquisa tradicional normalmente ignora. $O$ objetivo é partilhar e provocar mudanças pessoais e sociais num maior número de pessoas".

Para esta metodologia os projetos de investigação estão relacionados aos acontecimentos transformadores nas vidas dos pesquisadores, acontecimentos que modificaram pensamentos, sentimentos e senso de mundo. A elaboração de uma autoetnografia somente se justifica quando o conteúdo que será o foco da investigação possui, de fato, alguma relevância e possa trazer contribuição significativa ao campo da pesquisa sociológica. Não cumprindo com esse propósito algumas produções nessa área têm sido consideradas superficiais. 
O autoetnógrafo, ao usar a sua voz em primeira pessoa e escrever a partir do seu ponto de vista, faz do seu posicionamento uma narrativa decididamente subjetiva. Neste modelo de investigação, a reflexividade assume um lugar central e o destaque é dado ao conteúdo político de quem fala, ou seja, do narrador. Anderson (citado por Santos, 2017, p.223) aponta uma característica central da autoetnografia: "o pesquisador é um ator social altamente visível dentro do texto escrito. Os próprios sentimentos e experiências do pesquisador são incorporados à história e considerados como dados vitais para a compreensão do mundo social que está sendo observado."

Segundo Andrade (2016, p.2), "na autoetnografia escreve-se pessoalmente com emoção, abertura à vulnerabilidade, com desafio, contrapondo o texto ortodoxo, que pretende ser objetivo, racional e textualmente distanciado". A autoetnografia se torna uma abordagem adequada para a minha investigação por me possibilitar recordar "experiências de vida poderosas" (Hard and Williams, 2010, p.451).

Voltarei a minha memória ao que vivi para recuperar tudo aquilo que foi matéria-prima da organização do meu trabalho, assim como os meus erros e as dificuldades que enfrentei, a fim de que "o sujeito da experiência adquira, agora, o estatuto analítico de objeto de observação" (Santos, 2017, p.215).

Dentro dos procedimentos de análise na autoetnografia, é possível utilizar diversas técnicas: "diários de campo compostos por factos registrados e reflexões de quem investiga, bem como pensamentos, impressões pessoais sobre os indivíduos envolvidos e percepções; e entrevistas analisando formas de falar e de agir sobre a utilização de espaços e lugares, arquitetura, ou ainda sobre artefactos como roupas, textos, livros, filmes e fotografias" (Kock, Godoi \& Lenzi citados por Andrade, 2016, p.4). Para a composição desta pesquisa autoetnográfica as minhas experiências pessoais serão os principais instrumentos de análise.

\section{METODOLOGIA}

Para a composição desta pesquisa autoetnográfica as minhas experiências pessoais foram os principais instrumentos de análise, sendo este um método indutivo onde "o conhecimento é fundado exclusivamente na experiência" (Gil, 2010, p.10). 
Para isso retomei os meus diários de campo, outros materiais meus escritos no passado, textos lidos, livros que foram importantes neste meu percurso, filmes tanto assistidos como produzidos referentes aos Projetos que realizei, registros fotográficos e dentre os artefactos estão roupas e peças artesanais confeccionadas durante Projetos realizados. Ou seja, foi importante em um primeiro momento eu recuperar tudo aquilo que considerei matéria-prima da organização do meu trabalho ao longo dos últimos dez anos. As técnicas de recolha de dados incluíram ainda desenhos, e-mails e conversar informais, "os dados obtidos a partir destas fontes têm um denominador comum: a sua análise depende fundamentalmente das capacidades integradoras e interpretativas do investigador"(Coutinho, 2018, p.331). Nas minhas notas de campo localizei expressões descritivas e reflexivas, sendo muito presente nos meus apontamentos as expressões dos meus sentimentos a partir do que observei.

"Writing as a process of discovery" diz Ellis (2019, p. 3), referência nos estudos autoetnográficos. O meu exercício intelectual será de retomar acontecimentos marcantes na minha trajetória, nos últimos dez anos, com o objetivo de criar categorias que possam contribuir para eu oferecer capacitação para mulheres interventoras sociais que tenham interesse em desenvolver Projetos Sociais voltados a mulheres marginalizadas. Porém, pelo fato deste estudo autoetnográfico, até este momento, não ter sido concluídos, as categorias de análise ainda serão criadas, com rigor, à medida que o trabalho se desdobrar. Serão elaborados instrumentos de análise para essas categorias.

Quando iniciei a trabalhar para o sistema de saúde pública do Brasil, foi sentada durante oito horas por dia, de segunda a sexta-feira, durante quase dois anos, ouvi relatos de inúmeras violências, físicas, psicológicas e sexuais de muitas outras mulheres. Relatos de maus tratos, faltas, ausências, negligências e misérias, de uma população que considero um sintoma social: pessoa que por falta de oportunidades não faziam parte desta engrenagem esmagadora chamada sistema capitalista. E que por isso são compreendidas como "o refugo da sociedade, o catarro, o resto, o lixo" (grifo meu). Foram muitas as histórias de vida que me marcaram, fisionomias e rostos de mulheres que creio que nunca mais vou esquecer. Histórias que parecem não serem somente negligências do Estado, mas negligências de Deus. Exploração do ambiente de trabalho verso falta de oportunidade de trabalho. Lembro de uma senhora idosa que sentou a minha frente, na sua primeira consulta, e a primeira frase que saiu da sua boca foi "hoje eu só tenho laranjas na minha casa para comer", e complementou "eu queria ter bolachas para poder dar aos meus netos", então ela começou a chorar. Como se acolhe emocionalmente essa dor? A dor de só ter 
laranjas? Essa mulher sofria de fome, essa era a dor dela. Ela não precisava de uma psicóloga, ela precisava de comida. Uma outra menina, de 17 anos, sentou a primeira vez a minha frente e perguntou-me "você quer saber o meu problema?", "o meu problema é que eu sou preta e pobre". Frases como essas eu nunca me esqueci e ao ouvi-las entendi que o sofrimento destas mulheres é o que hoje compreendo como um sofrimento ético político.

Esse conceito é uma categoria psicossocial de análise que descreve aquilo que localizei no meu trabalho como Psicóloga Social trabalhando com mulheres em vulnerabilidade ao longo dos últimos dez anos: o impacto das questões social nas subjetividades e saúde emocional destas mulheres. "O sofrimento demarcado não é um sofrimento de ordem individual, proveniente de desajustamentos e desadaptações, mas um tipo de sofrimento determinado exclusivamente pela situação social da pessoa" (Bertini, 2014, p. 62).

A atenção que vem sendo dada no campo da Saúde Mental as mulheres em situação de vulnerabilidade social no Brasil, no campo das Políticas Públicas oferecidas pelo Estado, apresenta-se como insuficiente e ineficiente. As Políticas Públicas de Saúde no Brasil, e em outros países, não possuem um recorte de género, os serviços públicos oferecem apenas psicotrópicos e antidepressivos para sintomatologias que são de ordem social. A controvérsia destas intervenções está na constatação que o tratamento medicamentoso somente alivia os sintomas das mulheres que vivenciam diferentes níveis de precarização, quando as demandas sociais causadoras dos sofrimentos envolvidos, que deveriam ser o real foco de extrema atenção, não são sanadas. O sofrimento ético-político é a dor advinda das injustiças sociais, embora todos estamos submetidos a essas injustiças, "a humilhação, a vergonha, a depreciação, são vividas de forma mais intensa pelas classes subalternas" (Bertini, 2014, p.65).

Estive com mulheres que não tinham acesso a um simples absorvente menstruavam, algumas improvisavam introduzindo miolo de pão em suas vaginas. Ouvindo o relato das histórias de vida destas mulheres olho-no-olho. Eu não estava estudando esta realidade somente partir de dados estatísticos, mas eu estava falando com essas pessoas face-aface. Eu estava diante de vidas que passam por invisíveis para a sociedade, mas meus olhos estão ali, vendo-as. E ali eu via elas passam frio, ficarem doentes, via o lugar onde defecavam e sentia os odores. Numa altura deste meu trabalho, como eu tinha o hábito de abraçar os meus pacientes, eu tive uma infestação de sarna pelo meu corpo todo. Foi preciso lavar todas as minhas roupas e forro de cama em água quente, tomei medicação, o 
meu corpo coçava de forma desesperadora e depois ficou todo marcado. Aquela foi a única vez que tive sarna na minha vida, pelo fato de não terem acesso a saneamento básico e estarem expostos a lixos e esgoto a céu aberto essas mulheres convivem com situações e doenças como essa frequentemente.

A sala em que eu atendia no sistema público de saúde foi reduzida e o espaço foi dividido por uma parede pela metade, passei a ter um espaço pequeno para realizar os atendimentos e com pouco ventilação. Os conteúdos emocionais que eu ouvia eram muito densos e naquele espaço pequeno pareciam ter se intensificados dentro de mim, no final de dois anos deste trabalho quem adoeceu psicologicamente fui eu. Finalizei esse trabalho por não ter mais condições psicológicas de permanecer, fui hospitalizada. Anos depois tive na minha cabeça uma infestação grave de piolho no Kenya, trabalhando num Projeto com mulheres seropositivas numa comunidade com as condições mais precárias que já vi em toda a minha vida. Quando somos interventores sociais os nossos corpos também são afetados por essas realidades pelas quais transitamos, mas a grande diferença é que depois que o nosso trabalho termina nós podemos ir embora daquele local, enquanto aquelas pessoas continuam permanecendo ali.

Lembro como se fosse hoje o frio na minha barriga antes de adentrar a primeira vez no pátio de um Hospital Psiquiátrico para realizar umas das minhas Oficinas, minhas mãos suavam. Ao passar pelos corredores com portas trancadas com chaves a todo o momento, ouvia os gritos de algumas das pacientes, ouvia barulhos de mulheres batendo nas grades, com nos filmes, outras amarradas nas camas de contenção. Quando entrei pela primeira vez no pátio deste Hospital lembro-me de uma senhora, toda nua, corcunda, que me olhou nos olhos e, em seguida, passou a urinar no chão, na minha frente. A cada Projeto a expectativa hoje é sempre a mesma: a de desaprender. O que não quero é ser mais uma cientista social com apenas conhecimentos teóricos e distanciada do mundo, quero habitar o mundo para que ele me diga como devo intervir. Por isso preciso estar no campo, para suspender o meu intelectualismo, preciso ver, tocar com as minhas mãos e cheirar. Preciso estar diante de situações que me calem e que, ao mesmo tempo, me perturbem. Esses Projetos mudam a minha relação com o tempo e espaço, educam-me não somente a olhar, mas ensina-me a estar atenta aos detalhes do agora e capturar os instantes com os ouvidos. São nutrientes com os quais venho adubando o meu sentir e refletir como cientista social. Sinto que carrego em mim todos esses instantes vividos, no exercício autoetnográfico "you may come 
to understand yourself in deeper ways. And with undestanding yourself comes understanding others" (Ellis, 2019, xviii).

Agora sou feita um pouco da urina daquela mulher, e de todas as demais multidões que já vivi, sou feita dos pincéis de tinta das Oficinas de Arte-Terapia que conduzi, dos papeis, dos recortes, das fragrâncias, cores, pétalas, tecidos, texturas e músicas. Sou também feita de tudo aquilo que é sujo, encardido, podre, pobre e que fede. Já vi luz e escuridão, beleza no lixo, o que dói e alegra. Depois de vários outros Projetos Sociais que já realizei, percebi que quando a ideia de um Projeto nasce dentro de mim, nasce junto um novo saber, novas vontades, novas descobertas, um novo eu. Eu renasço a cada Projeto que eu escrevo, pois, sou eu que me reescreve como pessoa. A autoetnografia é um método qualitativo que compreende "la investigación, no sólo como una práctica, un ejercicio o una tarea, sino también como un estilo de vida lleno de sentido" (Calva, 2019, p.84).

\section{CONCLUSÃO}

Os contributos pessoas que a auto-etnografia trouxeram-me como investigadora foi de constar que dizer ser feminista, antirracista e anticapitalista parece-me permitir um certo status como investigadora em ciências sociais, enquanto na realidade aquilo que realmente somos muitas vezes não revelamos a ninguém, nem a nós mesmos. A medida que fui trabalhando na estrita do meu texto autoetnográfico, a auto-experiência refletiva que esta metodologia me permitiu, fez-me retomar memórias que denunciaram os meus preconceitos, racismos e estigmas que eu mesma reproduzi durante muitos momentos das minhas práticas junto a estar mulheres com as quais atuei, o exercício autoetnográfico educa-me e ensina que "ser reflexivo requiere ser consciente de nosotros mismos. Debemos vigilar-nos como tomadores de decisiones, agentes y actores" (Calva, 2019, p.88).

Os contributos deste estudo para a sociedade consiste em ter mulheres capacitadas para desenvolverem Projetos Sociais voltados as demandas de mulheres em situação de pobreza, com isso, que possam produzir impacto e resultados efetivos para o bem-estar e saúde mental desta parcela da população. As beneficiárias desta proposta serão tanto as mulheres que irão receber a capacitação, quanto as mulheres para as quais as suas ações serão destinadas. A relevância desta auto-etnografia para as pesquisas qualitativas é demonstrar que um estudo pode conter conteúdos pessoais e emocionais do investigador e não por isso ser menos analítico, rigoroso e teórico. Segundo Calva (2019, p. 157) "la autoetnografía como método puede dar lugar a textos emocional e intelectualmente poderosos 
que se extienden muy fuera de la página, los cuales afectan audiencias y comunidades. Los autoetnógrafos, por ello, deben considerar las consecuencias en lo personal, social, político y ético, cuando utilizan sus experiencias como fuente de datos de la investigación primaria".

O problema de investigação foi formulado a partir da minha experiência de trabalho como Psicóloga Social, tendo experiencia de contacto direto com mulheres que vivenciam diferentes níveis de precarização constatei que os governos têm feito pouco frente as demandas destas mulheres subalternas. As suas reivindicações não aparecem como pauta em muitos debates políticos atuais, muito menos há um retorno em forma de Políticas Públicas. Considerando a saúde mental destas mulheres, a partir de uma perspectiva interseccional, e para a garantia dos seus direitos, é preciso que haja uma mobilização das mulheres da sociedade civil para a elaboração de Projetos Sociais que atendam necessidades básicas em diversas áreas, tais como alimentação, moradia, saúde, educação, transporte e lazer. Por esta razão, diante deste cenário de insuficiências, a capacitação de mulheres da sociedade civil para se tornarem interventoras sociais se torna uma estratégia importante e urgente.

Todos os riscos psicossociais vivenciados por mulheres em vulnerabilidade (desemprego, violências, dupla jornada de trabalho, etc.), quando somados ao apoio familiar insuficiente, produzem profundos sentimentos de insegurança e fazem com que muitas dessas mulheres experienciem os seus sofrimentos de forma solitária e desprotegida.

O impacto psicológico dessas circunstâncias conduz a sentimentos de desesperança intensos, gerando altos níveis de stresse, ansiedade, quadros depressivos, experiências de trauma e tentativas de suicídio. Muitas destas mulheres não possuem forma de gerar renda, por isso algumas são dependentes de pais ou de maridos. Além de assumirem a função doméstica e o cuidado dos filhos, a condição dessa dependência económica as coloca em situações de exploração dentro do próprio lar. Quando saem para o mercado de trabalho encontram empregos informais, trabalhos mal remunerados, onde acabam também sendo exploradas. "Além dos riscos ecológicos, assiste-se a uma precarização crescente e massiva das condições de existência, com uma individualização da desigualdade social e de incerteza quanto às condições de emprego, tornando-se a exposição aos riscos generalizados" (Mendes, 2015, p.23), o que faz com que o sofrimento ético-político destas mulheres só se agravem. 


\section{REFERÊNCIAS}

Andrade, C. (2016). Autoetnografia. Questões aprofundadas de Investigação. Universidade de Coimbra. Faculdade de Economia/Faculdade de Psicologia e de Ciências da Educação.1-7

Almeida, Helena Neves. 2012. Novas e inovadoras ofertas sociais: conhecimento científico e competência profissional. In Novos desafios na educação. Responsabilidade social, democracia e sustentabilidade. , 211 - 235. ISBN: 978-85-7963-087-3. Brasilia: Editora LiberLibro.

Bertini, Fatima Maria Araújo. 2014. O Sofrimento Ético-Político: Uma Análise do estado da arte. Psicologia \& Sociedade: $60-69$.

Calva, S. M. B. (2019). Autoetnografía: Uma metodología cualitativa (1st ed.). México: Universidade Autónoma de Aguascalientes \& El Colegio de Sant Luis.

Coutinho, C. P. (2011). Metodologia de Investigação em Ciências Sociais e Humanas: Teoria e Prática. Coimbra: A Imedina.

Ellis, C. (2004). The Ethnographic: A Methodological Novel about Autoethnography. Walnut Creek, CA: AltaMira Press.

Gil, A. C. (2010). Métodos e técnicas de Pesquisa Social (6th ed.). São Paulo: Atlas

Hart, S. J., \& Williams, D. J. (2010). Blending Voices: Autoethnography as a Vehicle for Critical Reflection in Social Work, Journal of Teaching in Social Work, 30:4, 450-467, DOI: 10.1080/08841233.2010.515911

Maluf, S. e Tornquist, C. (2010). Gênero, saúde e aflição: abordagens antropológicas. SC: Letras Contemporâneas. Florianopolis.

Mendes, J. (2015). Sociologia do risco. Uma breve introdução e algumas lições. Coimbra: Imprensa da Universidade de Coimbra.

Santos, S. M. (2017). O método da autoetnografia na pesquisa sociológica: atores, perspectivas e desafios. Plural, 214-241. hnps://doi.org/10.11606/issn. 2176-8099 .pcso. 2017.113972 